\title{
Factors influencing the approaches to studying of preclinical and clinical students and postgraduate trainees
}

\author{
Dakshitha P Wickramasinghe and Dharmabandu N Samarasekera*
}

\begin{abstract}
Background: Students can be classified into three categories depending on their approaches to studying; namely, deep approach (DA), strategic approach (SA) and surface apathetic or superficial approach (SAA). The aim of this study was to identify factors affecting the approaches to studying among Sri Lankan medical undergraduates and post graduate trainees and to analyze the change in the pattern of study skills with time and experience.

Method: Pre-clinical and clinical students of the Faculty of Medicine, University of Colombo and postgraduate trainees in Surgery at the National Hospital of Sri Lanka were invited to complete the Approaches and Study Skills Inventory for Students (ASSIST) questionnaire.

Results: $A$ total of 187 pre clinical $(M: F=96: 91), 124$ clinical $(M: F=61: 63)$ and 53 post graduate trainees ( $M: F=$ 50:3) participated in the study. Approaches of male and female students were similar. SA was significantly affected by age among the preclinical students $(p=0.01)$, but not in other groups. Among pre-clinical students, males preferred a teacher who supported understanding $(p=0.04)$ but females preferred a passive transmission of information $(p<0.001)$. This, too, was not visible among other groups. A linear regression performed on group (batch), gender, island rank at GCE Advance Level (AL) examination, self appraisal score and the preference scores of type of teacher only managed to explain $35 \%$ or less of variance observed for each approach in individual groups.
\end{abstract}

Conclusion: Different factors affect the approach to studying in different groups but these explain only a small fraction of the variance observed.

\section{Background}

Students can approach an academic task focussing on understanding or reproducing. This in fact, was the basis of a landmark study in 1976 by Marton and Saljo [1]. These ideas were followed up by Entwistle [2] and Ramsden [3] in 1981 and 1992 respectively. Subsequent work demonstrated that different approaches will affect the outcome of study programs [4-6] and that there are significant differences between the East and the West [7]. The notion that students can change their learning approach however has conflicting evidence [8-10].

There are 3 main approaches to studying; i.e. Deep approach (DA), Superficial (or surface apathetic)

\footnotetext{
*Correspondence: samarasekera58@yahoo.co.uk

Department of Surgery, Faculty of Medicine, University of Colombo, Sri Lanka
}

\section{Biomed Central}

(c) 2011 Wickramasinghe and Samarasekera; licensee BioMed Central Ltd. This is an Open Access article distributed under the terms of the Creative Commons Attribution License (http://creativecommons.org/licenses/by/2.0), which permits unrestricted use, distribution, and reproduction in any medium, provided the original work is properly cited. approach (SAA) and Strategic approach (SA). ). DA is
an organised approach where the emphasis is internal and motivation comes from the relevance of the syllabus to their personal needs. SAA on the other hand, as the name itself implies, is superficial and includes memorisation and retrieval with unreflective associations. Learners with SA are mainly concerned about assessments and see studying as a game played to be won with various techniques like spotting potential questions from previous examination papers and making good personal impressions on the teachers.

The aims of this study were,

I. to identify the correlations between gender, age, self appraisal and preference for teacher type on the individual's approach to studying. 
II. to analyze the change in the patterns of study skills, from a cross-sectional perspective.

\section{Methods}

\section{Setting and participants}

The study population is comprised of the first year (preclinical) and the final year (clinical) medical students and postgraduate trainees in General Surgery

There were a total of 364 participants, 187 from the preclinical (M: $F=96: 91), 124$ from the clinical $(M: F$ $=61: 63$ ) and 53 post graduate trainees in Surgery (M: F $=50: 3)$.

For the undergraduates, the questionnaires were distributed at lectures. After explaining the purpose of the research, they were invited to complete and return the questionnaires. Postgraduates were approached individually during working hours and invited to participate in the study. All participants were assured confidentiality.

The undergraduate curriculum incorporates 5 streams which run parallel [11]; Introductory Basic Sciences Stream, Applied Sciences Stream, Clinical Sciences Stream, Behavioural Sciences Stream and Community Stream. Each academic year has 3 semesters and an examination at the end of each semester. The final pass mark is the cumulative total of results of all examinations held and the final MBBS examination.

The postgraduate training programme for registrars is coordinated by the Post Graduate Institute of Medicine (PGIM). They are first allocated to general surgical units for a year and later to speciality units for 2-3 monthly rotations.

The ethics committee of the Faculty of Medicine, University of Colombo (FMC) approved the study.

\section{The questionnaire}

The participants were given the Approaches and Study Skills Inventory for Students (ASSIST) questionnaire. It is a revised version of the ASI developed by Entwistle and his colleagues at Lancaster University in the late 1970s and a product of the Enhancing Teaching-Learning Environments in Undergraduate Courses (ETL) team [12].

Respondents answer the questionnaire using 5 point modified Likert scales (1 -disagree and 5 - agree). The first part includes 6 statements and deals with the respondent's perception of learning. The second part deals with the actual approaches to studying. This contains 52 statements combined into 13 subscales of four items each, which are then further grouped into the three main scales: DA, SA, and SAA. The third part containing 8 statements assesses the preference of course type and teaching methods and was answered using a like-dislike scale (1- definitely like, 5- definitely dislike). A final question asks the respondent to self evaluate himself/herself about previous assessments and was used as the self appraisal score used in the analysis. The English version of ASSIST has been validated by Byrne et al [13].

\section{Statistical analysis}

This was a cross sectional study to test the hypothesis that the approaches to studying are different between undergraduates and post graduates.

The data were entered into a SPSS datasheet (SPSS Inc, Chicago, IL) and cumulative scores calculated as instructed in the ASSIST questionnaire. Each of the 52 statements was primarily attributed to one approach, and the cumulative score for each approach was the sum of the values of these statements.

The effect of group on each approach as well as preference of the type of teacher was analysed using the Kruskal-Wallis test (data not shown). Spearman correlation was used to assess the correlation between age and scores of each approach. The effect of gender was analysed using the Mann-Whitney test. Unless otherwise specified, analysis was done separately for each approach and group (e.g. -DA of pre-clinical, DA of clinical, etc). The relationships between the score of each approach with the other variables were analyzed using linear regression analysis. Significance level for the testing was $<0.05$, unless otherwise specified.

\section{Results}

The questionnaire return rate was $99.4 \%$ for pre-clinical students, $68.8 \%$ for clinical students and $96.3 \%$ for post graduates and $86.0 \%$ cumulatively. The scores of each group for each approach are shown in table 1.

There was a significant correlation between DA and SA $(\rho=0.51, p<0.001)$ and a small correlation between DA and SAA $(\rho=0.214, p<0.001)$. There was no correlation between SA and SAA $(\rho=0.056, p=0.143)$. In all three groups, SA had the highest median score, followed by DA. SAA had the lowest median. Pre-clinical and PG trainees had the highest mean for DA, while Clinical students had the highest mean for SAA and Pre clinical students for SA.

\section{Effect of age and gender}

There were no statistically significant differences seen between male and female students of each group and the median scores of the approaches to studying (table 2).

There was a significantly positive correlation between age and SA among the preclinical students $(\rho=0.206, \mathrm{p}=$ .002 ), but no other significant relationship was seen in other groups for any of the approaches (table 3) (figure 1).

Among pre clinical students, gender had a statistically significant effect on the preference of the type of teacher, where the males preferred a teacher who 
Table 1 The scores of each group for each approach

\begin{tabular}{|c|c|c|c|c|}
\hline \multicolumn{2}{|c|}{$\begin{array}{c}\text { Approach } \\
\text { Group }\end{array}$} & \multirow{2}{*}{$\begin{array}{c}\text { Deep Approach } \\
62.00\end{array}$} & \multirow{2}{*}{$\begin{array}{c}\text { Surface Apathetic Approach } \\
47.00\end{array}$} & \multirow{2}{*}{$\begin{array}{c}\text { Strategic approach } \\
67.00\end{array}$} \\
\hline Pre-clinical & Median & & & \\
\hline \multirow[t]{2}{*}{$N=187$} & Minimum & 41 & 15 & 39 \\
\hline & Maximum & 77 & 72 & 82 \\
\hline Clinical & Median & 57.00 & 52.00 & 58.50 \\
\hline \multirow[t]{2}{*}{$N=124$} & Minimum & 16 & 16 & 17 \\
\hline & Maximum & 82 & 72 & 81 \\
\hline Post graduate in training & Median & 62.00 & 50.00 & 64.00 \\
\hline \multirow[t]{3}{*}{$N=53$} & Minimum & 46 & 26 & 49 \\
\hline & Maximum & 78 & 70 & 81 \\
\hline & Chi-square & 32.794 & 15.643 & 66.617 \\
\hline \multirow[t]{2}{*}{ Kruskal Wallis test } & df & 2 & 2 & 2 \\
\hline & Sig. & .000 & .000 & .000 \\
\hline \multirow[t]{3}{*}{ Significance } & Pre-clinical Vs. Clinical & $P<0.001$ & $P<0.001$ & $P<0.001$ \\
\hline & Clinical Vs. PG & $P<0.001$ & $P=0.105$ & $P<0.001$ \\
\hline & Pre-clinical Vs PG & $P=0.669$ & $P=0.075$ & $P=0.03$ \\
\hline
\end{tabular}

supported understanding $[\mathrm{U}=3743.5, \mathrm{p}=0.04$, $]$ and females preferred a passive transmission of information $[\mathrm{U}=3094.5, \mathrm{p}<0.001]$. This difference was not visible among the clinical students [SU $(\mathrm{U}=1671, \mathrm{p}=0.104)$, TI $(\mathrm{U}=1897.5, \mathrm{p}=0.456$ ] or the PG trainees [SU $(\mathrm{U}=$ $60.5, \mathrm{p}=0.318)$, TI $(\mathrm{U}=70, \mathrm{p}=0.43)]$.

\section{Regression analysis}

Multiple regression analysis was performed for each approach separately for undergraduate (i.e. pre-clinical and clinical students) and post graduates. Gender, self appraisal score and the preference scores of a teacher supporting understanding and transmitting information were the variables included. Island rank at AL examination was used as a variable only in undergraduates. This was because the postgraduates belonged to several AL batches and their island ranks would not provide a comparable result (Undergraduates - Table 4, Postgraduates - Table 5).
Among the undergraduates, there were statistically significant relationships between the group and supporting understanding with scores obtained for each approach. In addition self appraisal score was statistically significant for SAA and SA and the preference for a teacher who transmits information with SAA. The variables were able to predict $23 \%$ of variance of DA score, $13 \%$ of variance in SAA score and $35 \%$ of the variance of SA score.

There were no significant associations between any of the parameters analyzed and the preference of PG students. The models only explained $3 \%, 2 \%$ and $<1 \%$ of DA, SAA and SA. (Table 5)

\section{Discussion}

The results of the study indicate that the 3 groups essentially have different approaches to studying. In addition the correlation between age, gender, self appraisal and preference of a particular teaching type is

Table 2 The effect of gender on approaches to studying

\begin{tabular}{|c|c|c|c|c|c|c|c|c|c|c|c|}
\hline \multirow[b]{2}{*}{ Pre Clinical } & \multirow[b]{2}{*}{ Mean (male, female) } & \multicolumn{2}{|c|}{ DA } & \multicolumn{2}{|c|}{ SAA } & \multicolumn{2}{|c|}{ SA } & \multicolumn{2}{|c|}{$\mathrm{TI}$} & \multicolumn{2}{|c|}{ SU } \\
\hline & & 61.9 & 60.8 & 46.4 & 47.5 & 66.2 & 66.4 & 14.5 & 16.0 & 16.0 & 15.5 \\
\hline & Mann-Whitney U & \multicolumn{2}{|c|}{3950.5} & \multicolumn{2}{|c|}{4126.0} & \multicolumn{2}{|c|}{4237.0} & \multicolumn{2}{|c|}{3088.0} & \multicolumn{2}{|c|}{3743.5} \\
\hline & Asymp. Sig. (1-tailed) & \multicolumn{2}{|c|}{.130} & \multicolumn{2}{|c|}{.257} & \multicolumn{2}{|c|}{.362} & \multicolumn{2}{|c|}{0.0007} & \multicolumn{2}{|c|}{0.08} \\
\hline \multirow[t]{3}{*}{ Clinical } & Mean (male, female) & 55.7 & 55.7 & 51.7 & 51.8 & 57.1 & 57.1 & 15.7 & 15.7 & 14.9 & 15.9 \\
\hline & Mann-Whitney U & \multicolumn{2}{|c|}{1822.500} & \multicolumn{2}{|c|}{1876.000} & \multicolumn{2}{|c|}{1869.000} & \multicolumn{2}{|c|}{1897.5} & \multicolumn{2}{|c|}{1671.0} \\
\hline & Asymp. Sig. (1-tailed) & \multicolumn{2}{|c|}{.310} & \multicolumn{2}{|c|}{.410} & \multicolumn{2}{|c|}{.397} & \multicolumn{2}{|c|}{0.12} & \multicolumn{2}{|c|}{0.2} \\
\hline \multirow[t]{3}{*}{ Post graduate } & Mean (male, female) & 62.1 & 59.6 & 49.7 & 40.3 & 64.6 & 67.0 & 12.2 & 11.7 & 16.6 & 16.0 \\
\hline & Mann-Whitney U & \multicolumn{2}{|c|}{47.500} & \multicolumn{2}{|c|}{36.500} & \multicolumn{2}{|c|}{51.500} & \multicolumn{2}{|c|}{70.0} & \multicolumn{2}{|c|}{60.5} \\
\hline & Asymp. Sig. (1-tailed) & \multicolumn{2}{|c|}{.144} & \multicolumn{2}{|c|}{.069} & \multicolumn{2}{|c|}{.182} & \multicolumn{2}{|c|}{0.85} & & \\
\hline
\end{tabular}


Table 3 Effect of age on approaches to studying

\begin{tabular}{|c|c|c|c|c|}
\hline & & $\mathrm{DA}$ & SAA & SA \\
\hline \multirow[t]{2}{*}{ Preclinical } & Correlation coeffieicient & -.033 & .031 & .206 \\
\hline & Sig. & $=.657$ & .675 & .005 \\
\hline \multirow[t]{2}{*}{ Clinical } & Correlation coeffieicient & .054 & .108 & .060 \\
\hline & Sig. & .549 & .232 & .509 \\
\hline \multirow[t]{2}{*}{ PG } & Correlation coeffieicient & .110 & .078 & .050 \\
\hline & $\overline{\text { Sig. }}$ & .494 & .630 & .755 \\
\hline
\end{tabular}

also different between the groups. The roughly equal gender distribution is the norm seen at our medical school. Rather high response rate of preclinical students may be attributed to the free education system in Sri Lanka and students being grateful and cooperative. Lesser response rate from the clinical students may be because they are more occupied (i.e. clinical work and preparation for the final examination) than the preclinical students and this is understandable. The authors believe the PGs being individually approached resulted in the high return rate.

\section{Effect of the group}

Of the 3 groups, the clinical students had the lowest score for DA. Though the decline in DA is surprising at first glance, this is a well described phenomenon in the West [14] but not in the East [15]. Previous articles that studied non-medical undergraduate and postgraduate trainees failed to identify any significant difference between them [16,17]. Our findings confirm this as far as preclinical students and PG students are concerned.

The increase in the superficial approach with the progression of the undergraduate course has been described previously in Australia [14] but not seen in a study conducted in Indonesia [15]. The pattern of scores of SA of the undergraduates in our study, correlates with the findings of Emilia et al [15] and that of preclinical students with PGs with the findings of Richardson et al [16]. We believe that the excessive workload of the undergraduate curriculum makes the clinical students adopt a superficial, less deep approach which may favour assessments.

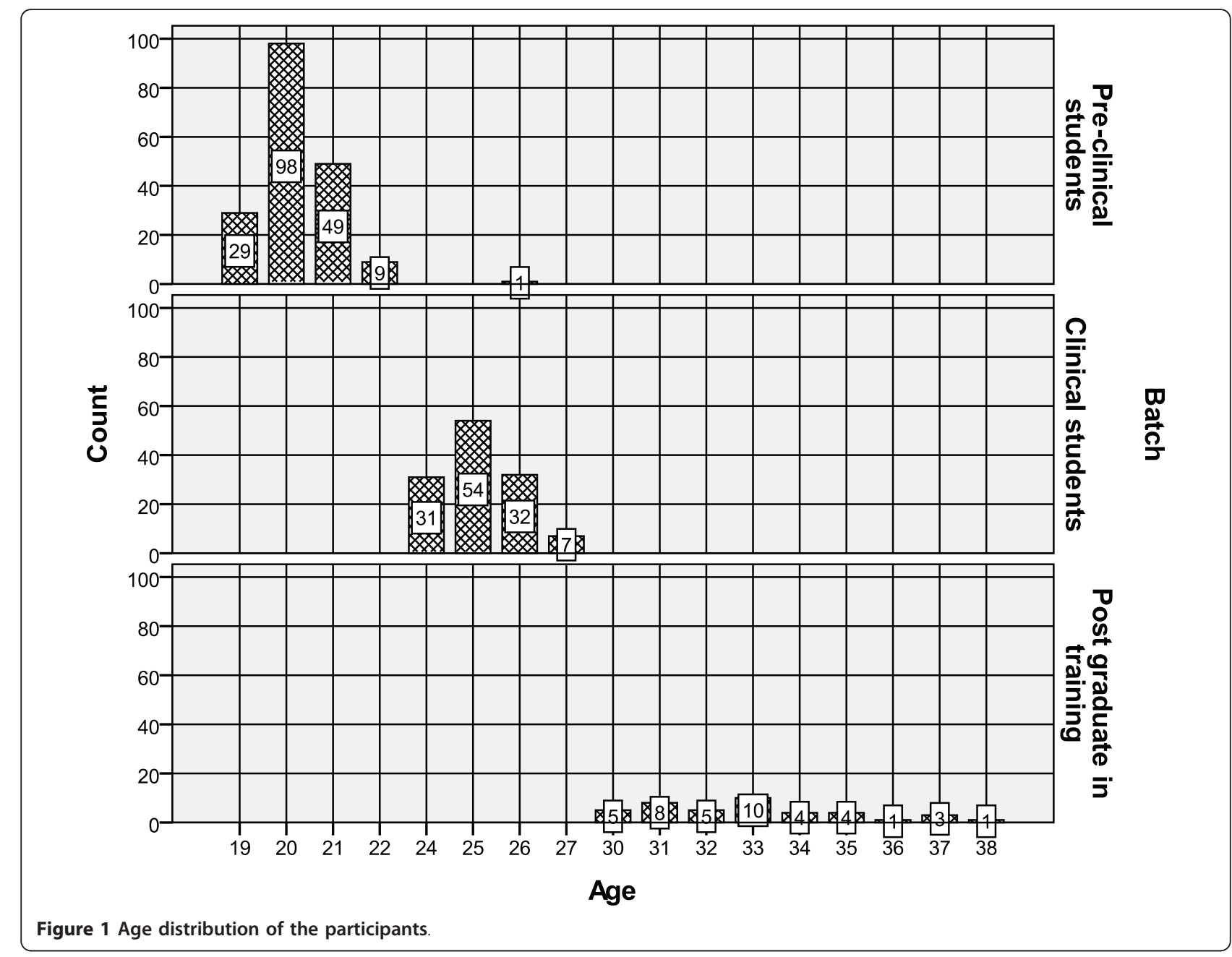


Table 4 Undergraduates

\begin{tabular}{|c|c|c|c|c|c|c|c|c|c|c|}
\hline & & \multicolumn{3}{|c|}{ DA } & \multicolumn{3}{|c|}{ SAA } & \multicolumn{3}{|c|}{ SA } \\
\hline \multirow[t]{2}{*}{ Model summary } & $R$ & \multicolumn{3}{|c|}{0.505} & \multicolumn{3}{|c|}{0.395} & \multicolumn{3}{|c|}{0.608} \\
\hline & Adjusted R square & \multicolumn{3}{|c|}{0.236} & \multicolumn{3}{|c|}{0.135} & \multicolumn{3}{|c|}{0.353} \\
\hline \multirow[t]{6}{*}{ ANOVA } & $\mathrm{F}$ & \multicolumn{3}{|c|}{13.79} & \multicolumn{3}{|c|}{7.465} & \multicolumn{3}{|c|}{23.595} \\
\hline & Sig. & \multicolumn{3}{|c|}{$<0.0001$} & \multicolumn{3}{|c|}{$<0.0001$} & \multicolumn{3}{|c|}{$<0.0001$} \\
\hline & & B & SE of $B$ & $\beta$ & B & SE of $B$ & $\beta$ & B & SE of $B$ & $\beta$ \\
\hline & (Constant) & 46.130 & 4.908 & & 28.450 & 5.973 & & 50.305 & 5.293 & \\
\hline & Batch & -5.257 & 1.041 & -.297 & 3.297 & 1.267 & .163 & -8.067 & 1.123 & -.389 \\
\hline & Gender & -.505 & .990 & -.029 & -.106 & 1.205 & -.005 & .817 & 1.068 & .040 \\
\hline \multirow[t]{4}{*}{ Coefficients } & Island rank & -.001 & .007 & -.006 & .012 & .008 & .088 & .001 & .007 & .008 \\
\hline & Self appraisal & .222 & .393 & .034 & -1.385 & .478 & -.183 & 2.248 & .424 & .290 \\
\hline & Supporting understanding & 1.060 & .178 & .339 & .505 & .217 & .141 & .618 & .192 & .169 \\
\hline & Transmitting information & .197 & .164 & .068 & .912 & .199 & .275 & -.052 & .176 & -.015 \\
\hline
\end{tabular}

DA - Deep approach

SAA - Superficial Apathetic Approach

SA - Strategic approach

\section{Effect of gender}

The effect of gender in approaches to learning is a question that has intrigued generations. Our results failed to identify any significant difference, in keeping with the findings of the Indonesian study of Emilia et al [15] as well as other studies $[18,19]$.

\section{Effect of age}

The only significant observation in our study was the fact that, among the preclinical students, the SA increased with age and to the authors' knowledge, this is the first time this association is being reported. Though the correlation is small $(\rho=0.206)$, we feel it is important. Since AL examination is held only once a year the increase in age in the participants is accounted for by the increase number of attempts at the AL examination.
This may suggest that students tend to be more strategic with the increased pressure of repeating the same examination which itself is probably the most competitive examination a doctor will have to sit in his life. The absence of this phenomenon among the clinical students could be due to the influence of the medical curriculum, since it has been at least 5 years since they sat for their $\mathrm{AL}$ examination. Both above factors suggest that this is a remnant effect of the AL examination. However it is important to remember that age and the group are confounders.

Work of Aaron et al [20] describes a different association of SAA and increased age. Another study done among medical students failed to identify any relationship between age and approaches to studying [16] but, studies done among business students [21] as well as

Table 5 Postgraduates

\begin{tabular}{|c|c|c|c|c|c|c|c|c|c|c|}
\hline & & \multicolumn{3}{|c|}{ DA } & \multicolumn{3}{|c|}{ SAA } & \multicolumn{3}{|c|}{ SA } \\
\hline \multirow[t]{2}{*}{ Model summary } & $R$ & \multicolumn{3}{|c|}{0.330} & \multicolumn{3}{|c|}{0.317} & \multicolumn{3}{|c|}{0.169} \\
\hline & Adjusted $\mathrm{R}$ square & \multicolumn{3}{|c|}{0.028} & \multicolumn{3}{|c|}{0.019} & \multicolumn{3}{|c|}{-0.060} \\
\hline \multirow[t]{4}{*}{ ANOVA } & $\mathrm{F}$ & \multicolumn{3}{|c|}{1.342} & \multicolumn{3}{|c|}{1.228} & \multicolumn{3}{|c|}{0.325} \\
\hline & \multirow[t]{2}{*}{ Sig. } & \multicolumn{3}{|c|}{$P=0.27$} & \multicolumn{3}{|c|}{$P=0.313$} & \multicolumn{3}{|c|}{$P=0.859$} \\
\hline & & B & SE of $B$ & $\beta$ & B & SE of $B$ & $\beta$ & B & SE of $B$ & $\beta$ \\
\hline & (Constant) & 53.637 & 9.295 & & 45.027 & 17.556 & & 53.870 & 10.272 & \\
\hline \multirow[t]{4}{*}{ Coefficients } & Gender & -2.341 & 3.462 & -.097 & -9.193 & 6.539 & -.203 & 2.691 & 3.826 & .105 \\
\hline & Self appraisal & -.827 & .948 & -.138 & -.994 & 1.791 & -.088 & .131 & 1.048 & .021 \\
\hline & Supporting understanding & .716 & .423 & .246 & .758 & .799 & .138 & .419 & .468 & .136 \\
\hline & Transmitting information & .338 & .235 & .223 & 616 & .443 & .217 & .026 & .259 & .016 \\
\hline
\end{tabular}

DA - Deep approach

SAA - Superficial Apathetic Approach

SA - Strategic approach 
students of degrees in psychology, sociology and social anthropology [22] describe an increase of DA with age, not $\mathrm{SA}$ as our results suggest.

\section{Preference of teacher types}

The undergraduates preferred a teacher who "transmitted information" more than the postgraduates. This may have been brought on by the total transformation of teaching, where the undergraduate curriculum is mainly based on lectures, tutorials and discussions, and the postgraduate curriculum is mainly student centred and self motivated.

Our findings of the female preference of a teacher who passively transmits information is in keeping with the results of a study conducted by Severiens et al [19] also.

\section{Regression analysis}

The associations between gender and group have been described above.

The island rank at AL examination (i.e. an indicator of examination performance) did not show a significant correlation for any approach. Even the present evidence on this issue is conflicting, with a review article that associates DA and SAA with better examination performance [23] and another that associates SAA with better performance at examinations [20]. However, studies done previously in Sri Lanka [24] as well as in Pakistan [25] have failed to demonstrate a similar performance benefit.

High self appraisal was negatively associated with the DA and SAA in pre-clinical students and positively with SA in both pre-clinical as well as clinical students. There were no associations seen with DA. Although there are no articles that deal with this association, Simon Cassidy in his article [26] describes a correlation between DA and self assessment skills. The absence of a relationship between self appraisal and DA together with the absence of an association between DA and examination performance, when considered in the light of the interpretations of Cassidy [26] could mean that a sub-factor of DA that correlates with examination performance and self appraisal may be missing in Sri Lankan students.

\section{Conclusions}

The approaches to studying among Sri Lankan medical students are affected by the group and age (within the group) but not gender. The preference of the type of teacher is affected by the group and age and by gender among preclinical students. The findings suggest that characteristics of Sri Lankan students are some what different to students of other countries in the region. This is an important consideration in formulating the local curriculum. The decline in DA with progression in the medical school needs to be assessed and addressed by the curriculum developers. Perhaps a change in the frequency as well as the format of the assessments would be beneficial. It will also be worthwhile to improve the self-directed learning potential of undergraduate students.

There is no baseline value to compare the data for clinical students and post graduates and this is the main limitation of the present study. However, if the preclinical students are followed up and assessed at fixed intervals and if their approach as well as performance at examinations is assessed, perhaps more meaningful data could be obtained.

\section{Acknowledgements}

The authors would like to acknowledge the ETL team for the ASSIST questionnaire.

\section{Authors' contributions}

All authors were involved in planning, data collection, analysis of data and writing the manuscript. All authors read and approved the final manuscript.

\section{Competing interests}

The authors declare that they have no competing interests.

Received: 11 October 2010 Accepted: 20 May 2011

Published: 20 May 2011

\section{References}

1. Marton FSR: On qualitative differences in learning: I. Outcome and process. British Journal of Educational Psychology 1976, 46(1):4-11.

2. Entwistle N: Styles of Learning and Teaching; an integrated outline of educational psychology for students, teachers and lecturers. John Wiley; 1981.

3. Ramsden P: Learning to Teach in Higher Education. Routledge London; 1992.

4. Karen $M$, lan $D$, John $B$ : Approaches to learning and studying in medical students: validation of a revised inventory and its relation to student characteristics and performance. Medical Education 2004, 38(5):535-543.

5. McManus IC, Richards P, Winder BC, Sproston KA: Clinical experience, performance in final examinations, and learning style in medical students: prospective study. BMJ 1998, 316(7128):345-350.

6. Reid WA, Duvall E, Evans P: Relationship between assessment results and approaches to learning and studying in Year Two medical students. Med Educ 2007, 41(8):754-762.

7. Kember D, NG S, TSE H, Wong ETT, Pomfret M: An examination of the interrelationships between workload, study time, learning approaches and academic outcomes. Studies in Higher Education 1996, 21(3):347-358.

8. Lindemann R, Duek JL, Wilkerson L: A comparison of changes in dental students' and medical students' approaches to learning during professional training. Eur J Dent Educ 2001, 5(4):162-167.

9. Zeegers P: Approaches to learning in science: a longitudinal study. $\mathrm{Br} J$ Educ Psychol 2001, 71(Pt 1):115-132.

10. Bain PRTJD: Consistency in learning strategies. Higher Education 1982, 11(3):249-259.

11. Faculty of Medicine University of Colombo. [http://www.cmb.ac.lk/ academic/medicine/streams.html].

12. The project. [http://www.etl.tla.ed.ac.uk/project.html].

13. Byrne M, Flood B, Willis P: Validation of the approaches and study skills inventory for students (assist) using accounting students in the USA and Ireland: a research note. Accounting Education: An International Journal 2004, 13(4):449-459.

14. Stiernborg M, Bandaranayake RC: Medical students' approaches to studying. Medical Teacher 1996, 18(3):229-236. 
15. Emilia $\mathrm{O}$, Mulholland $\mathrm{H}$ : Approaches to learning of students in an Indonesian medical school. Medical Education 1991, 25(6):462-470.

16. Richardson JTE: Approaches to studying in undergraduate and postgraduate students. Studies in Higher Education 1998, 23(2):217-220.

17. Gibbs Ge: Improving the quality of student learning. 1992.

18. Richardson JTE: Gender differences in responses to the Approaches to Studying Inventory. Studies in Higher Education 1993, 18(1):3-13.

19. Severiens S, Dam GT: Gender and Gender Identity Differences in Learning Styles. Educational Psychology: An International Journal of Experimental Educational Psychology 1997, 17(1):79-93.

20. Aaron S, Skakun E: Correlation of students' characteristics with their learning styles as they begin medical school. Academic Medicine 1999, 74(3):260-262.

21. Duff A: Access policy and approaches to learning. Accounting Education: An International Journal 1999, 8(2):99-110.

22. Richardson JTE: Mature students in higher education: II. An investigation of approaches to studying and academic performance. Studies in Higher Education 1995, 20(1):5-17.

23. Ferguson E, James D, Madeley L: Factors associated with success in medical school: systematic review of the literature. BMJ 2002, 324(7343):952-957.

24. Kosala NMarambe, DHE PD, PD Indika SSomaratne, Piyaratne Chathura: Do medical students who claim to be using deep learning strategies perform better at the Forensic Medicine examination? South East Asian Journal of Medical Education 2009, 3(1):25-30.

25. Naqvi Z, Ahmed R: Learning approaches and academic performance of undergraduate medical students in Pakistan. J Pak Med Assoc 2000, 50(1):20-25

26. Cassidy S: Learning style and student self-assessment skill. Education + Training (UK) 2006, 48(2-3):170-177.

\section{Pre-publication history}

The pre-publication history for this paper can be accessed here: http://www.biomedcentral.com/1472-6920/11/22/prepub

doi:10.1186/1472-6920-11-22

Cite this article as: Wickramasinghe and Samarasekera: Factors influencing the approaches to studying of preclinical and clinical students and postgraduate trainees. BMC Medical Education 2011 11:22.

\section{Submit your next manuscript to BioMed Central and take full advantage of:}

- Convenient online submission

- Thorough peer review

- No space constraints or color figure charges

- Immediate publication on acceptance

- Inclusion in PubMed, CAS, Scopus and Google Scholar

- Research which is freely available for redistribution

Submit your manuscript at www.biomedcentral.com/submit 